\title{
Isolated Dissection of the Superior Mesenteric Artery
}

\author{
Takashi Watari ${ }^{1}$ and Yasuharu Tokuda ${ }^{2}$
}

Key words: isolated dissection of the superior mesenteric artery, abdominal pain of unknown origin

(Intern Med 57: 1059, 2018)

(DOI: 10.2169/internalmedicine.9361-17)
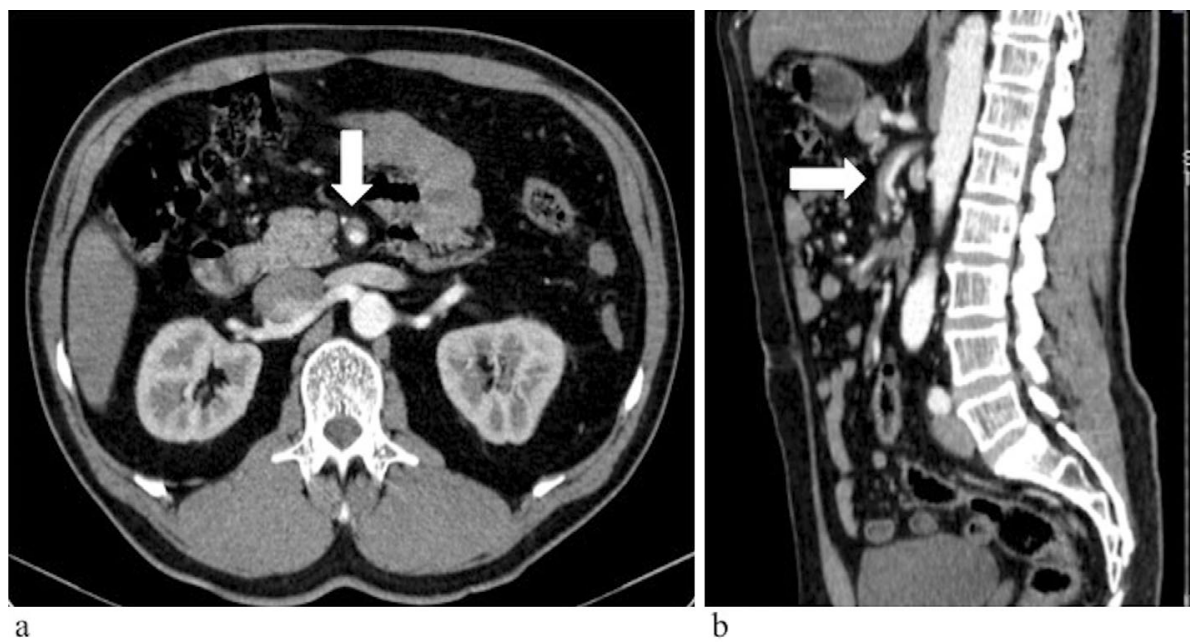

Picture.

Isolated dissection of the superior mesenteric artery (IDSMA) is considered as a rare disorder. We report a case of IDSMA that mimicked common causes of acute abdominal pain. A 52-year-old healthy man came to the emergency room with a sudden onset of moderate right lower quadrant and periumbilical abdominal pain for 2 hours. He also reported breaking out in a cold sweat for five minutes but denied any other symptoms. An abdominal examination revealed a flat and slightly tender right lower quadrant. Initial investigations, laboratory data and abdominal ultrasound were normal. We chose to focus on the continuous pain that had started at a precise moment he could clearly pinpoint, and contrast CT angiography was performed. The findings showed dissection with thrombosis in the proximal SMA (Picture $\mathrm{a}$ and $\mathrm{b}$ ). Although patients with this disease may undergo extensive workups for abdominal causes $(1,2)$, tak- ing a careful history concerning the instantaneous development of continuous pain is helpful for a quick diagnosis.

The authors state that they have no Conflict of Interest (COI).

\section{References}

1. Kimura $Y$, Kato $T$, Nagao $K$, et al. Outcomes and radiographic findings of isolated spontaneous superior mesenteric artery dissection. Eur J Vasc Endovasc Surg 53: 276-281, 2017.

2. Luan JY, Guan X, Li X, et al. Isolated superior mesenteric artery dissection in China. J Vasc Surg 63: 530-536, 2016.

The Internal Medicine is an Open Access article distributed under the Creative Commons Attribution-NonCommercial-NoDerivatives 4.0 International License. To view the details of this license, please visit (https://creativecommons.org/licenses/ by-nc-nd/4.0/).

${ }^{1}$ Postgraduate Clinical Training Center, Shimane University Hospital, Japan and ${ }^{2}$ Okinawa Muribushi Project for Teaching Hospitals, Japan Received: April 18, 2017; Accepted: July 19, 2017; Advance Publication by J-STAGE: December 8, 2017

Correspondence to Dr. Takashi Watari, wataritari@gmail.com

(C) 2018 The Japanese Society of Internal Medicine. Intern Med 57: 1059, 2018 